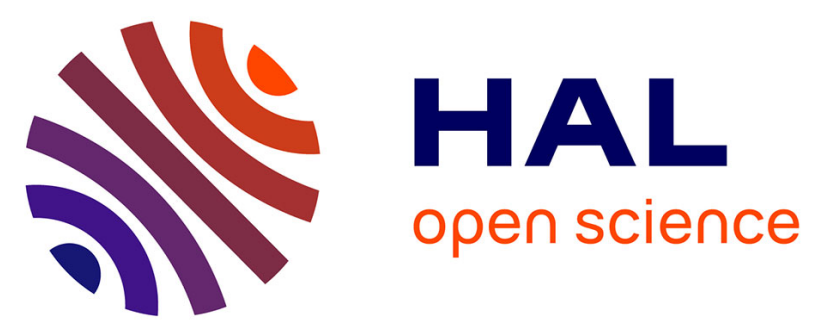

\title{
Atypical synergetic effect between Te- and V-substituted phosphomolybdic cesium salt and LAMOX-type phases for the oxidation of isobutane into methacrylic acid
}

\author{
Q. Huynh, A. Selmi, G. Corbel, P. Lacorre, J. M. M. Millet
}

\section{- To cite this version:}

Q. Huynh, A. Selmi, G. Corbel, P. Lacorre, J. M. M. Millet. Atypical synergetic effect between Te- and V-substituted phosphomolybdic cesium salt and LAMOX-type phases for the oxidation of isobutane into methacrylic acid. Journal of Catalysis, 2009, 266 (1), pp.64-70. 10.1016/j.jcat.2009.05.016 . hal-00431136

\author{
HAL Id: hal-00431136 \\ https://hal.science/hal-00431136
}

Submitted on 19 Jul 2019

HAL is a multi-disciplinary open access archive for the deposit and dissemination of scientific research documents, whether they are published or not. The documents may come from teaching and research institutions in France or abroad, or from public or private research centers.
L'archive ouverte pluridisciplinaire HAL, est destinée au dépôt et à la diffusion de documents scientifiques de niveau recherche, publiés ou non, émanant des établissements d'enseignement et de recherche français ou étrangers, des laboratoires publics ou privés. 


\title{
Atypical synergetic effect between Te- and V-substituted phosphomolybdic cesium salt and LAMOX-type phases for the oxidation of isobutane into methacrylic acid
}

\author{
Q. Huynh ${ }^{\mathrm{a}}$, A. Selmi ${ }^{\mathrm{b}}$, G. Corbel ${ }^{\mathrm{b}}$, P. Lacorre ${ }^{\mathrm{b}}$, J.M.M. Millet ${ }^{\mathrm{a}, *}$ \\ a Institut de recherches sur la catalyse et lânvironnement de Lyon, Université Lyon 1, CNRS, UMR 5256, \\ IRCELYON, 2 avenue Albert Einstein, F-69626 Villeurbanne, France \\ ${ }^{b}$ Laboratoire des Oxydes et Fluorures, Université du Maine - \\ Avenue Olivier Messiaen, F-72085 Le Mans Cedex 9, France
}

\begin{abstract}
Mechanical-phase mixtures of a phosphomolybdic cesium salt containing $\mathrm{V}$ and Te as counter-cations and $\alpha-\mathrm{La}_{2} \mathrm{Mo}_{2} \mathrm{O}_{9}$ (LM) or $\beta-\mathrm{La}_{2} \mathrm{Mo}_{1.9} \mathrm{~V}_{0.1} \mathrm{O}_{8.95}$ (LMV) have been studied as catalysts for the partial oxidation of isobutane into methacrylic acid (MAA) and methacrolein (MA). The catalysts with $50 \mathrm{wt} . \%$ of LMV in the phase mixture appeared very efficient at $360^{\circ} \mathrm{C}$ and atmospheric pressure with selectivity and yield into MAA and MA, respectively, equal to $59 \%$ and $12.4 \%$. The characterization of the catalysts allowed to propose that the synergetic effect taking place between the phases results primarily from a support effect of the lanthanum molybdate stabilizing the phosphomolybdic salt and preventing its sintering. The origin of such effect has been related to crystallographic fits between the two phases. This type of structurerelated synergetic effect had never been reported in catalytic oxidation reaction for which most of the time, the spreading of one phase on the other is taking place.
\end{abstract}

Phosphomolybdic cesium salt Lanthanum molybdate

\section{Keywords}

Synergetic effect

Heterogeneous catalysis
Isobutane oxidation

Methacrylic acid.

\section{Introduction}

Efficient heterogeneous catalysts for selective oxidation of light alkanes are still of substantial importance in catalytic technology. The design of a catalyst for the direct oxidation of isobutane to methacrylic acid and methacrolein with a high productivity is especially interesting although few progresses have been made since the Keggin-type heteropolyoxometalate catalysts developed in the $90 \mathrm{~s}$.

The optimization of the existing Keggin-type heteropolyacid catalysts has led to very complex formula with partial substitutions of cations in the polyanions (As to $\mathrm{P}$ and $\mathrm{V}$ to $\mathrm{Mo}$ ) and as counter-cations [1-4]. If productivity high enough for industrial applications has been claimed on such compounds, the stability in reactions conditions and the methacrolein to methacrylic acid selectivity should still be improved. With that respect, some of us have recently proposed new catalysts based on the Keggin-type phosphomolybdic cesium salts with protons partially substituted by tellurium and vanadium [5]. These catalysts have been shown to be as efficient as most of those already patented but also very stable. The most efficient catalyst corresponded to the formula $\mathrm{Cs}_{2} \mathrm{Te}_{0.3}(\mathrm{VO})_{0.1} \mathrm{H}_{\mathrm{x}} \mathrm{PMo}_{12} \mathrm{O}_{40}$ ( $\mathrm{CsTeV}$ phase). The tellurium and vana-

\footnotetext{
* Corresponding author. Fax: +334725399.

E-mail address: jean-marc.millet@ircelyon.univ-lyon1.fr (J.M.M. Millet).
}

dyl cations introduced as counter-cations and more or less randomly distributed in the cesium salt were shown to cap the Keggin anion and to promote the selectivity to MAA and the isobutane conversion, respectively. Furthermore, they appeared to stabilize the phosphomolybdic anions avoiding their partial decomposition in the catalytic reaction conditions [5].

Further modification of the formula of the catalysts appeared detrimental to their stability in the reaction conditions. One way to improve the efficiency of the Keggin-type heteropolycompounds catalysts, which has not been extensively explored up to now, is to search for synergetic effects between these compounds and other phases. These synergy effects can generally be observed when the phases are simply tested in mechanical mixtures with each other.

In this paper, we report on the study of mechanical mixtures of the fast oxide-ion conductor $\mathrm{La}_{2} \mathrm{Mo}_{2} \mathrm{O}_{9}(\mathrm{LM})$ with the most efficient Keggin-type heteropolycompound ( $\mathrm{CsTeV}$ ) as catalyst for the oxidation of isobutane into methacrolein (MA) and methacrylic acid (MAA). A $5 \mathrm{~mol} \%$ partial substitution of molybdenum by vanadium has been shown to stabilize the cubic highly conducting and disordered $\beta-\mathrm{La}_{2} \mathrm{Mo}_{2} \mathrm{O}_{9}$ form at room temperature [6]. Since such substitution had a positive effect on the catalytic properties of the phase in the oxidation of isobutane, we have used this substituted lanthanum molybdate to study the catalytic properties of the phase mixtures in dilute reaction gas feeds. 


\section{Experimental}

\section{Catalysts preparation}

The Te- and V-substituted phosphomolybdic cesium salt ( $\mathrm{CsTeV}$ ) was synthesized as described previously [7]. The tellurium-containing cesium salts were first prepared by dropwise addition of $0.4 \mathrm{~mL}$ of an aqueous solution containing $1.3 \mathrm{~g}$ of cesium chloride to a $140 \mathrm{~mL}$ aqueous solution of $8.16 \mathrm{~g}$ of phosphomolybdic acid and various amounts of telluric acid. After $1 \mathrm{~h}$ under stirring at $80^{\circ} \mathrm{C}$, the solution was dried at reduced pressure and the solid obtained, which was dried at $125^{\circ} \mathrm{C}$ and calcined under a flow of air at $360{ }^{\circ} \mathrm{C}$ for $6 \mathrm{~h}$. Vanadium was then introduced by maintaining the cesium salt re-hydrated at room temperature in air for $3 \mathrm{~h}$, under reflux and then stirring in a solution of toluene containing vanadium acetylacetonate $\left(\mathrm{V}\left[\mathrm{C}_{5} \mathrm{O}_{2} \mathrm{H}_{7}\right]_{3}\right.$ FLUKA $1347-$ 99-8). The solid dried under reduced pressure at $60{ }^{\circ} \mathrm{C}$ was not calcined but directly used for the preparation of the phase mixtures or heated under the catalytic reaction flow when tested as pure phase.

The low temperature monoclinic a form of $\mathrm{La}_{2} \mathrm{Mo}_{2} \mathrm{O}_{9}$ (LM) has been prepared by solid-solid reaction between $\mathrm{MoO}_{3}$ and $\mathrm{La}_{2} \mathrm{O}_{3}$. $\mathrm{La}_{2} \mathrm{O}_{3}$ was previously heated up to $1000{ }^{\circ} \mathrm{C}$ in order to remove adsorbed water and carbon dioxide [8]. To prepare $\beta$ - $\mathrm{La}_{2} \mathrm{Mo}_{1.9} \mathrm{~V}_{0.1} \mathrm{O}_{9}$ (sample LMV1), $\mathrm{V}_{2} \mathrm{O}_{5}$ was partially substituted to molybdenum oxide for the preparation of the ternary oxide. The starting oxides were weighted with the chosen stoichiometry and mixed by cogrinding by hand. The solid mixture was then introduced in an alumina crucible to be heat treated at $500{ }^{\circ} \mathrm{C}$. It was then subjected to heating and grinding several times in acetone to homogenize it until a single LAMOX phase was obtained. For pure $\mathrm{La}_{2} \mathrm{Mo}_{2} \mathrm{O}_{9}$, two heat treatments for $15 \mathrm{~h}$ at $900{ }^{\circ} \mathrm{C}$ were enough, whereas for $\mathrm{La}_{2}$ $\mathrm{Mo}_{1.9} \mathrm{~V}_{0.1} \mathrm{O}_{8.95}$, seven heat treatments for $15 \mathrm{~h}$ at $925^{\circ} \mathrm{C}$ were necessary. This was because the transitory formation of $\mathrm{LaVO}_{4}$ was difficult to avoid. Two other $\beta$ - $\mathrm{La}_{2} \mathrm{Mo}_{1.9} \mathrm{~V}_{0.1} \mathrm{O}_{9}$ samples have been prepared with higher- and lower-specific surface area. The sample with a higher surface (LMV2) was prepared using the thermal decomposition of [La, Mo, V] metal chelate complexes. Citric acid (CA) was used as a chelating agent in the molar ratio $\mathrm{CA} / M \approx 6$ $(M=[\mathrm{La}]+[\mathrm{Mo}]+[\mathrm{V}])$. A sticky gel is obtained on a hot plate by slowly evaporating the solution at $110^{\circ} \mathrm{C}$ for a few hours, and by drying the product at $120^{\circ} \mathrm{C}$ for about $30 \mathrm{~min}$. The calcination of this gel was carried out in air at $300^{\circ} \mathrm{C}$ for $5 \mathrm{~h}$. The fine powder obtained, which was brown in color, was then hand ground and fired twice at $560{ }^{\circ} \mathrm{C}$ (temperature determined from TG/DT analyses performed on Q600SDT TA instruments apparatus) under pure oxygen flow ( $1 \mathrm{~atm}$ ) for $1 \mathrm{~h}$ and $2 \mathrm{~h}$, respectively. The sample with a lowerspecific surface area (LMV3) was prepared by simply calcining the LMV2 sample at $900^{\circ} \mathrm{C}$ for $12 \mathrm{~h}$. The phase mixtures were obtained by mixing the respective powders and hand grinding them for 5-10 min. They were designated according to their nominal composition. For example, CsTeV-LM (50-50) denotes a solid containing the same weight of $\mathrm{La}_{2} \mathrm{Mo}_{2} \mathrm{O}_{9}$ and $\mathrm{Cs}_{2} \mathrm{Te}_{0.3}(\mathrm{VO})_{0.1^{-}}$ $\mathrm{H}_{x} \mathrm{PMo}_{12} \mathrm{O}_{40}$.

\section{Catalysts characterization}

The pure phases and physical-phase mixtures have been characterized by different techniques. X-ray powder diffraction (XRD) patterns were collected at room temperature with a Brüker D5005 diffractometer using the Ni-filtered $\mathrm{Cu}-\mathrm{K} \alpha$ radiations. They were recorded with $0.02^{\circ}(2 \theta)$ steps in the angular range of 3-80 with $1 \mathrm{~s}$ counting time per step.

Chemical analysis was determined by atomic emission for Mo, $\mathrm{V}, \mathrm{Te}$, and $\mathrm{P}$, using an induced plasma technique, and for Cs, using an air-acetylene flame on a SPECTROLAME-ICP from SPECTRO. Specific surface areas were measured by the BET method on a Micromeritics ASAP 2020 instrument by adsorption of liquid nitrogen on the samples after desorption at $250{ }^{\circ} \mathrm{C}$ for $3 \mathrm{~h}$ under secondary vacuum. The precision of the measurements was $0.1 \mathrm{~m}^{2} \mathrm{~g}^{-1}$.

Raman spectra were recorded using a DILOR XY spectrophotometer equipped with an intensified photodiode array detector. The emission line at $514.5 \mathrm{~nm}$ from an ArC ion laser (Spectra Physics, Model 2016) was used for excitation at low power (about $1 \mathrm{~mW}$ ). The particle size and morphology of the solids (fresh, after reaction conditions) were examined through a Hitachi S800 scanning electron microscope $(25 \mathrm{kV})$. Powdered specimens were spread on the SEM slabs and sputtered with gold.

\section{Catalytic testing}

The oxidation of isobutane was performed in a fixed bed reactor operating at atmospheric pressure under conditions described elsewhere [5]. The catalytic properties were determined between 310 and $360^{\circ} \mathrm{C}$ in a conventional flow reactor with a catalyst amount of either $0.5,1$ or $2 \mathrm{~g}$. Two feedstock compositions with different $\mathrm{O}_{2}: \mathrm{C}_{4} \mathrm{H}_{10}$ ratios and dilutions into $\mathrm{N}_{2}\left(\mathrm{O}_{2}: \mathrm{C}_{4} \mathrm{H}_{10}: \mathrm{H}_{2} \mathrm{O}: \mathrm{N}_{2}=\right.$ $30.3: 22.4: 10: 37.3$ or $10: 10: 10: 70)$ but the same water content and gas hour space velocity $\left(2500 \mathrm{~h}^{-1}\right)$ have been used to test the catalysts. The gases at the outlet of the reactor (isobutane, isobutene, $\mathrm{CO}$, and $\mathrm{CO}_{2}$ ) were analyzed on line with an on-line gas chromatograph with Porapak-Q and CP-Molsieve columns. The organic substrates, methacrolein (MA), acetic acid (AcA), methacrylic acid (MAA), acrylic acid (Acry), and acetone (Ace) were condensed during the reaction and analyzed off-line [5]. The catalytic data were collected after at least $8 \mathrm{~h}$ in the reaction conditions and for at least $48 \mathrm{~h}$. No change in catalytic properties was observed during this time. Blank tests without catalyst have been performed to show that homogeneous reaction was negligible in the range of temperature studied. Carbon balances have been calculated and were satisfactory for all the runs to within $\pm 2 \%$. The catalyst was recovered after a rapid quenching from the reaction temperature to room temperature with a concomitant shift of the reaction gas flow to a nitrogen flow.

\section{Results}

The chemical analyzes of the pure phases (CsTeV, LM, and LMV) were in good agreement with the desired stoichiometries and the presence of single phases was detected by X-ray powder diffraction. The CsTeV and LM phase mixtures with different relative phase ratios have first been tested as catalysts for the partial oxidation of isobutane into methacrylic acid. The results obtained are presented in Table 1 and in Fig. 1. The CsTeV phase was very active with a high selectivity to MAA, whereas the pure LM phase was very poorly active and mostly selective to isobutene. When the LM content increased up to $50 \%$ in the CsTeV-LM phase mixtures, the conversion slightly increased or remained constant whereas the selectivity to MMA increased passing through a maximum for about $20 \%$ of $\mathrm{LM}$. Isobutene, which was observed as a product on the LM phase, was not observed on the phase mixtures similarly to the CsTeV phase. At high LM content both the activity and the selectivity to MAA and MA decreased. This behavior of the catalysts was observed independently of the reaction temperature (Table 1). The apparent activation energies for the conversion of isobutane remained approximately the same for the phase mixtures as for the $\mathrm{CsTeV}$ catalyst $\left(\mathrm{E}_{\mathrm{a}}=76 \pm 3 \mathrm{kcal} / \mathrm{mol}\right)$, which tend to show that the same reaction mechanism was still present, and that it was the number of active sites that changed. 
Table 1

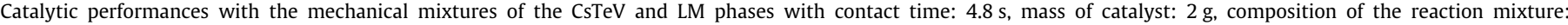
$\mathrm{iBu} / \mathrm{O}_{2} / \mathrm{H}_{2} \mathrm{O} / \mathrm{N}_{2}=27 / 13.5 / 10 / 49.5$; AcA: acetic acid, MAA: methacrylic acid, MA: methacrolein.

\begin{tabular}{|c|c|c|c|c|c|c|c|c|c|}
\hline \multirow[t]{2}{*}{ Catalyst } & \multirow[t]{2}{*}{$\mathrm{T}\left({ }^{\circ} \mathrm{C}\right)$} & \multirow[t]{2}{*}{ Conversion (\%) } & \multicolumn{6}{|c|}{ Selectivity (\%) } & \multirow{2}{*}{$\begin{array}{l}\text { Yield (\%) } \\
\text { MAA + MA }\end{array}$} \\
\hline & & & $\mathrm{CO}$ & $\mathrm{CO}_{2}$ & AcA & MAA & MA & Isobutene & \\
\hline LM & 361 & 1.7 & 9 & 8 & Trace & - & - & 83 & - \\
\hline \multirow[t]{2}{*}{ CsTeV } & 345 & 14.9 & 11 & 13 & 8 & 56 & 12 & - & 10.1 \\
\hline & 369 & 19.0 & 15 & 18 & 9 & 49 & 8 & - & 10.8 \\
\hline \multirow[t]{3}{*}{ CsTeV/LM (80/20) } & 312 & 10.1 & 3 & 8 & 4 & 77 & 8 & - & 8.5 \\
\hline & 345 & 16.1 & 9 & 12 & 9 & 62 & 8 & - & 11.2 \\
\hline & 369 & 18.0 & 13 & 15 & 8 & 57 & 7 & - & 11.5 \\
\hline \multirow[t]{3}{*}{ CsTeV/LM (70/30) } & 312 & 11.0 & 6 & 4 & 7 & 69 & 14 & - & 9.1 \\
\hline & 345 & 17.2 & 11 & 10 & 12 & 57 & 12 & - & 11.7 \\
\hline & 369 & 18.8 & 14 & 12 & 13 & 51 & 10 & - & 11.5 \\
\hline \multirow[t]{3}{*}{ CsTeV/LM (50/50) } & 315 & 11.1 & 5 & 3 & 6 & 72 & 13 & - & 9.4 \\
\hline & 358 & 17.8 & 10 & 11.5 & 13 & 54 & 12 & - & 11.4 \\
\hline & 368 & 18.5 & 12 & 12 & 15 & 49 & 11 & - & 11.1 \\
\hline
\end{tabular}

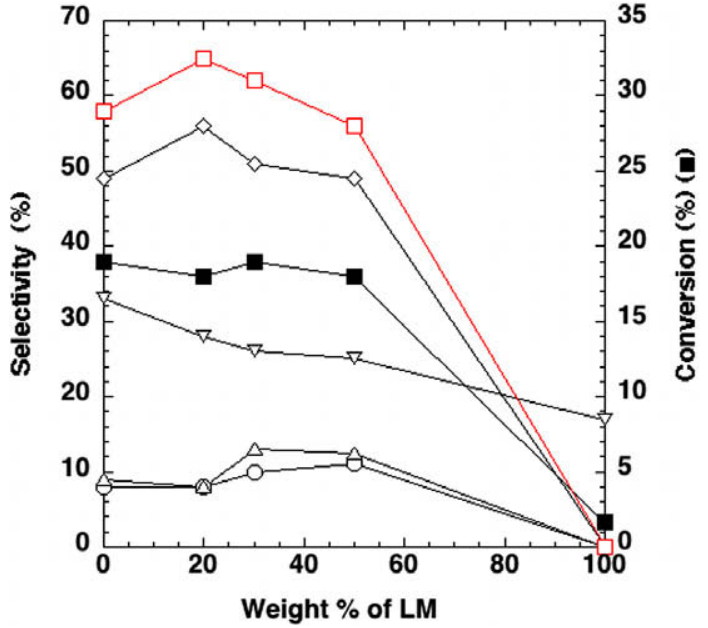

Fig. 1. Variation of the conversion of isobutane $(\boldsymbol{\square})$ and of the selectivity in $\mathrm{MAA}+\mathrm{MA}(\square), \operatorname{MAA}(\bullet), \mathrm{MA}(O), \operatorname{AcA}(\Delta)$, and $\mathrm{CO}_{x}(\nabla)$ as a function of the wt.\% of $\mathrm{LM}$ in the CsTeV-LM phase mixtures. The reaction was run at $369^{\circ} \mathrm{C}$; feedstock composition: $\mathrm{O}_{2} / \mathrm{C}_{4} \mathrm{H}_{10} / \mathrm{H}_{2} \mathrm{O} / \mathrm{N}_{2}=27 / 14 / 10 / 50$; total flow $=30 \mathrm{~mL} \mathrm{~min}^{-1}$.

The partially substituted lanthanum molybdate (LMV, $5 \mathrm{~mol} \%$ of vanadium) tested with a diluted feedstock appeared as poorly active as the pure LM phase but very selective to isobutene (Table 2 ). This phase, obtained with different specific surface areas, has been tested in mixture with the $\mathrm{CsTeV}$ phase in different conditions used in the patents (Table 2). First, it can be observed that in conditions closed but not exactly the same as those used for mixture with LM, a synergetic effect was observed as previously with the LM phase. The best yields in MA and MAA have been obtained with the most diluted charge $\left(\mathrm{iBu} / \mathrm{O}_{2} / \mathrm{H}_{2} \mathrm{O} / \mathrm{N}_{2}=10 / 10 / 10 /\right.$ 70). In this case, the activity of the phase mixtures remained high although it has a tendency to decrease with the LMV1 content. However, the selectivity to MAA and MA was stronger (Fig. 2). The CsTeV/LMV1 (50/50) catalyst tested in such conditions was among the most efficient catalysts for that reaction compared to those proposed in the patent literature [9-11]. The mixtures with the LMV2 and LMV3 phases presenting respectively a higher and a lower specific surface area (LMV2 with $11.8 \mathrm{~m}^{2} \mathrm{~g}^{-1}$ and LMV3 with $0.5 \mathrm{~m}^{2} \mathrm{~g}^{-1}$ ) were less active although more active than the CsTeV pure sample with equivalent mass. A synergetic effect was taking place but was much less intense. In the case of the phase mixture with LMV3, a large amount of $\mathrm{CsTeV}$ phase was not

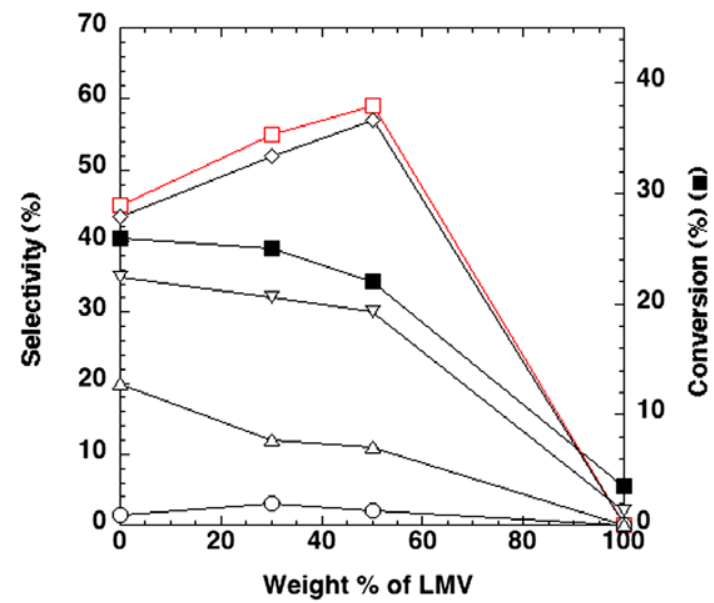

Fig. 2. Variation of the conversion of isobutane $(\boldsymbol{\square})$ and of the selectivity in $\mathrm{MAA}+\mathrm{MA}(\square), \operatorname{MAA}(\bullet), \operatorname{MA}(\bigcirc), \operatorname{AcA}(\triangle)$, and $\mathrm{CO}_{x}(\nabla)$ as a function of the wt.\% of LMV1 (LMV with $6 \mathrm{~m}^{2} \mathrm{~g}^{-1}$ ) in the CsTeV-LMV phase mixtures. The reaction was run at $360{ }^{\circ} \mathrm{C}$; feedstock composition: $\mathrm{O}_{2} / \mathrm{C}_{4} \mathrm{H}_{10} / \mathrm{H}_{2} \mathrm{O} / \mathrm{N}_{2}=10 / 10 / 10 / 70$; total flow $=$ $30 \mathrm{~mL} \mathrm{~min}^{-1}$

Table 2

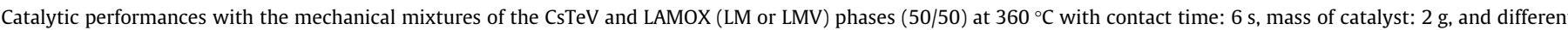

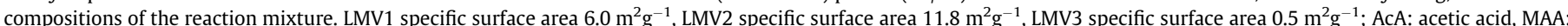
methacrylic acid, MA: methacrolein.

\begin{tabular}{|c|c|c|c|c|c|c|c|c|c|}
\hline \multirow[t]{2}{*}{ Catalyst } & \multirow[t]{2}{*}{$\mathrm{iBu} / \mathrm{O}_{2} / \mathrm{H}_{2} \mathrm{O} / \mathrm{N}_{2}$} & \multirow[t]{2}{*}{ Conversion (\%) } & \multicolumn{6}{|c|}{ Selectivity (\%) } & \multirow[t]{2}{*}{ Yield (\%) } \\
\hline & & & $\mathrm{CO}$ & $\mathrm{CO}_{2}$ & AcA & MAA & MA & Isobutene & \\
\hline LMV1 & $10 / 10 / 10 / 70$ & 3.5 & 1 & 1 & trace & - & - & 98 & - \\
\hline CsTeV/LMV1 & $10 / 10 / 10 / 70$ & 21 & 17 & 13 & 11 & 57 & 2 & - & 12.4 \\
\hline CsTeV & $40 / 20 / 10 / 30$ & 17.5 & 10 & 11 & 11 & 61 & 7 & - & 11.9 \\
\hline CsTeV/LMV1 & $40 / 20 / 10 / 30$ & 16 & 8 & 11 & 6 & 71 & 3 & - & 11.8 \\
\hline CsTeV/LMV2 & $40 / 20 / 10 / 30$ & 9.5 & 20 & 25 & 29 & 24 & 2 & - & 8.0 \\
\hline CsTeV/LMV3 & $40 / 20 / 10 / 30$ & 11.5 & 13 & 10 & 15 & 54 & 8 & - & 8.0 \\
\hline
\end{tabular}


supported and sintered whereas in the case of the LMV2, the supporting effect should be less efficient since the relative particle sizes of the two phases got closer and were not optimal. Furthermore in this last case a large part of the LMV2 particles were not coated and were active to oxidize the MAA and MA formed on the $\mathrm{CsTeV}$ phase to $\mathrm{CO}$ and $\mathrm{CO}_{2}$. This explains why the selectivity to MAA and MA strongly decreased (Table 2). In all cases, the catalysts properties appeared very stable with time in reactions conditions.

The phase mixtures have been characterized by X-ray diffraction before and after the catalytic testing. The patterns did not show any modification of the phase compositions or crystallinity after the co-grinding and testing. As an example, the X-ray diffraction patterns of the CsTeV-LM (50/50) phase mixture recorded before and after catalytic test are given in Fig. 3. The samples have also been studied by the Raman spectroscopy to try to detect surface modifications. The spectra recorded before and after catalytic testing were comparable and exhibited the same bands (Fig. 4). These bands corresponded to those characteristic of the Keggintype alkali salt $\left(991 \mathrm{~cm}^{-1}: v_{\mathrm{s}} \mathrm{Mo}=\mathrm{O}_{\mathrm{d}}, 974 \mathrm{~cm}^{-1}: v_{\mathrm{as}} \mathrm{Mo}=\mathrm{O}_{\mathrm{d}}\right.$

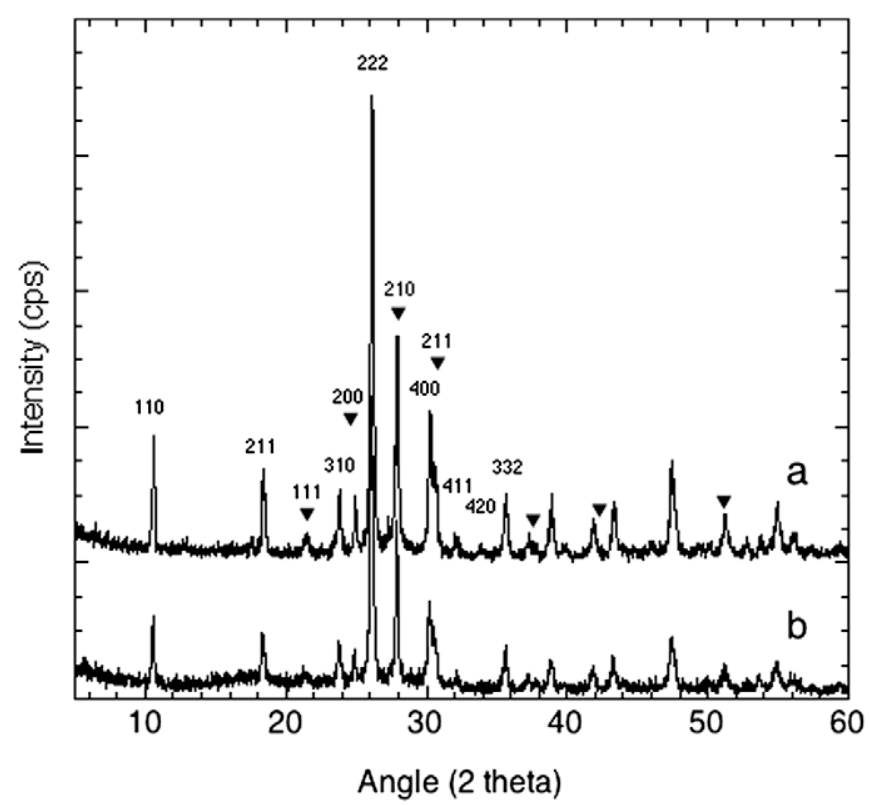

Fig. 3. X-ray diffraction patterns of the CsTeV-LM (50/50) phase mixture before (a) and after (b) catalytic test. $\mathbf{\nabla}: \mathrm{La}_{2} \mathrm{Mo}_{2} \mathrm{O}_{9}$. The patterns have been indexed up to $32^{\circ}(2 \theta)$.

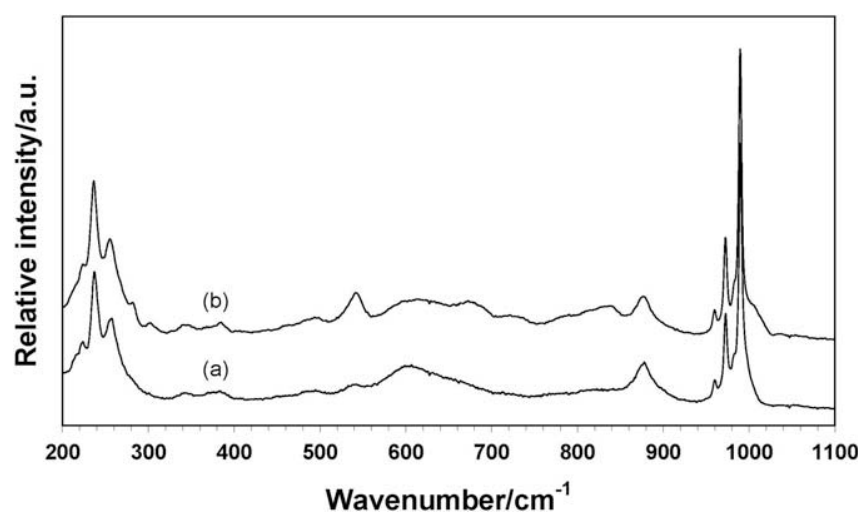

Fig. 4. Raman spectra of the CsTeV-LM (80/20) compound recorded before (a) and after (b) catalytic test at $360^{\circ} \mathrm{C}$. $\left.962 \mathrm{~cm}^{-1}: v_{\mathrm{s}} \mathrm{P}-\mathrm{O} 880 \mathrm{~cm}^{-1}: v_{\mathrm{as}} \mathrm{Mo}-\mathrm{O}_{\mathrm{b}}-\mathrm{Mo}\right)$ and to new peaks at $1024,1008,844,790,732,676,628,545,495,306,283$, and $183 \mathrm{~cm}^{-1}$ attributed to capped heteropolyanions bonds vibrations [5]. After catalytic testing, the catalysts should be more reduced (change in color from green to darker) and $\mathrm{Mo}^{5+}-\mathrm{Mo}^{6+}$ charge transfers in the Keggin unit enhanced. Since these charge transfers induced a Raman resonance, the bands related to the capped anions appeared stronger. The LM phase peaks were not detected in the spectra. This may certainly be related to the covering of the LM particles by the CsTeV ones.

\section{Discussion}

Synergetic effects between phases in heterogeneous oxidation catalysis may have different origins and it is difficult to unambiguously attribute it to one of those [12]. In our case, the characterization made by XRD and Raman spectroscopy after catalytic test did not show any chemical reaction between the phases. Furthermore, a bifunctional catalysis, with one phase catalyzing the oxidative dehydrogenation of isobutane and the other one catalyzing the oxidation of the formed isobutene cannot be retained as the main origin since the LM phase is very selective to isobutene but almost inactive. It restricts the possibilities of explanation to the formation of a coherent interface between the phases leading to a supporting effect.

It has been observed that the specific surface areas of heteropolycompounds when tested in oxidation reactions strongly decreased after testing. Such sintering effect, which is taking place systematically during the first hours on stream when the reaction temperature exceeds $300^{\circ} \mathrm{C}$, explains the strong decrease in the activity of this type of catalysts generally observed when the catalysts start to be tested. This phenomenon was also taking place for the pure $\mathrm{CsTeV}$ phase in the oxidation of isobutane during the first hours on stream (Fig. 5). The evolution after catalytic testing of the specific surface areas of the CsTeV and LM phases and their 50/50 phase mixture has been compared (Table 3). First, it can be observed that the specific surface area of the phase mixture prepared

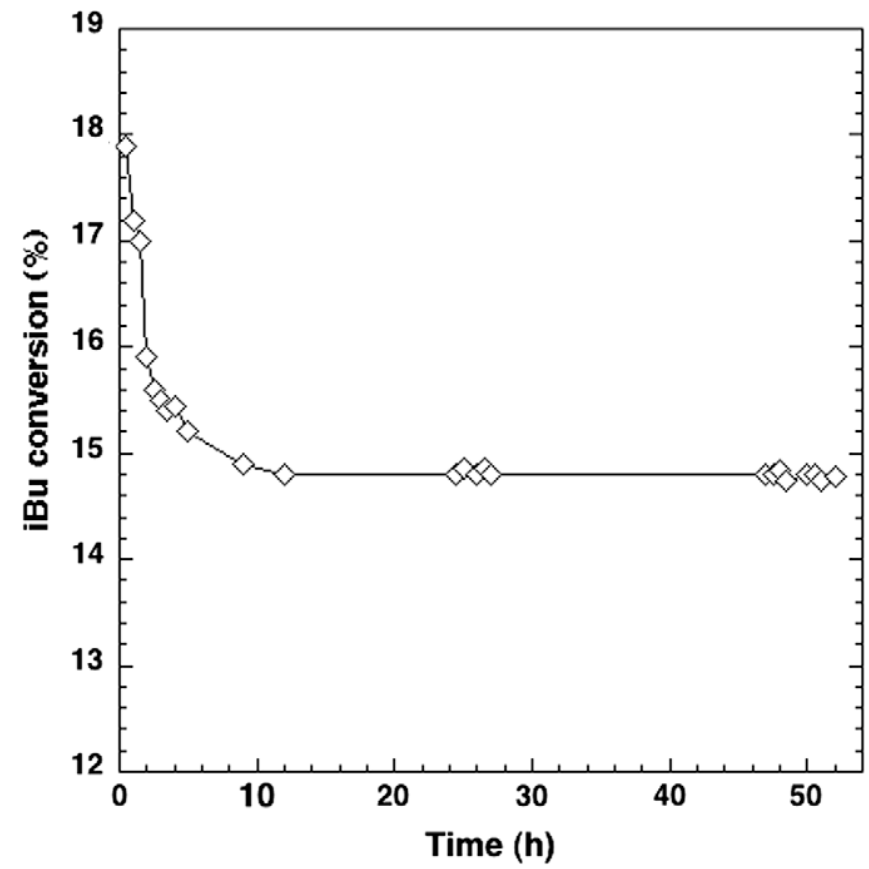

Fig. 5. Evolution of conversion as a function of time on stream for the $\mathrm{CsTeV}$ catalyst tested in standard conditions at $350^{\circ} \mathrm{C}$. 
Table 3

BET surface area of the compounds before and after catalytic testing

\begin{tabular}{llc}
\hline Compound & Before testing $\left(\mathrm{m}^{2} \mathrm{~g}^{-1}\right)$ & After testing $\left(\mathrm{m}^{2} \mathrm{~g}^{-1}\right)$ \\
\hline CsTeV & 22.0 & 11.4 \\
LM & 5.2 & 5.0 \\
CsTeV-LM (50/50) & $14.5(13.6)^{\mathrm{a}}$ & 13.2
\end{tabular}

a Theoretical value.

Table 4

Intrinsic rate of isobutane conversion on the heteropolycompound $(\mathrm{CsTeV})$ and the (50-50) phase mixture with lanthanum molybdate ( $\mathrm{CsTeV}+\mathrm{LM})$. For the calculations, specific surface areas measured after catalytic test have been considered with the hypothesis that the surface area of the LM phase was not modified in the reaction conditions. Contact time: $4.8 \mathrm{~s}$, mass of catalyst: $2 \mathrm{~g}$, composition of the reaction mixture: $\mathrm{iBu} / \mathrm{O}_{2} / \mathrm{H}_{2} \mathrm{O} / \mathrm{N}_{2}=27 / 13.5 / 10 / 49.5$.

\begin{tabular}{llll}
\hline Catalyst & $\mathrm{T}\left({ }^{\circ} \mathrm{C}\right)$ & $\begin{array}{l}\text { Rate of isobutane conversion } \\
\left(10^{8} \mathrm{~mol}^{-1} \mathrm{~m}^{-2}\right)\end{array}$ & $\begin{array}{l}\text { Rate of isobutane conversion } \\
\left(10^{8} \mathrm{~mol}^{-1} \mathrm{~m}_{\mathrm{CsTeV}}^{-2}\right)\end{array}$ \\
\hline CsTeV & 369 & 3.73 & 3.73 \\
CsTeV-LM & 368 & 3.12 & 3.84 \\
\hline
\end{tabular}

by co-grinding corresponded approximately to the average of those of the pure phases. Furthermore, only a small decrease in the specific surface area is observed for the phase mixture after catalytic testing, whereas the surface area of the pure CsTeV compound was divided by 2 . This result explains why the phase mixtures have an activity comparable to that of the pure $\mathrm{CsTeV}$ phase with up to $50 \%$ of LM. Indeed, if we hypothesize that the specific surface area of the phase mixture after catalytic test corresponds to the weighted sum of the specific surface area of the constituting phases as it is the case before catalysis, and that the surface of the LM phase in the phase mixture was not modified in the reaction conditions as it is the case when it is tested alone, the surface area of the CsTeV phase in the phase mixture after catalytic test can be evaluated and the intrinsic rate of isobutane conversion per square meter of $\mathrm{CsTeV}$ phase calculated. It appears that it is approximately the same as that calculated for the pure CsTeV phase (Table 4). The selectivity set is also comparable, which is in agreement with the hypothesis since it is the same active sites in comparable number that are exposed to the reactants.

To support the obtained results, a CsTeV-LM (70-30) sample has been characterized by scanning electron microscopy (Fig. 6). The comparison of the SEM micrographs recorded before and after catalytic testing clearly showed large particles covered with very small spherical-shaped particles. The first one should correspond

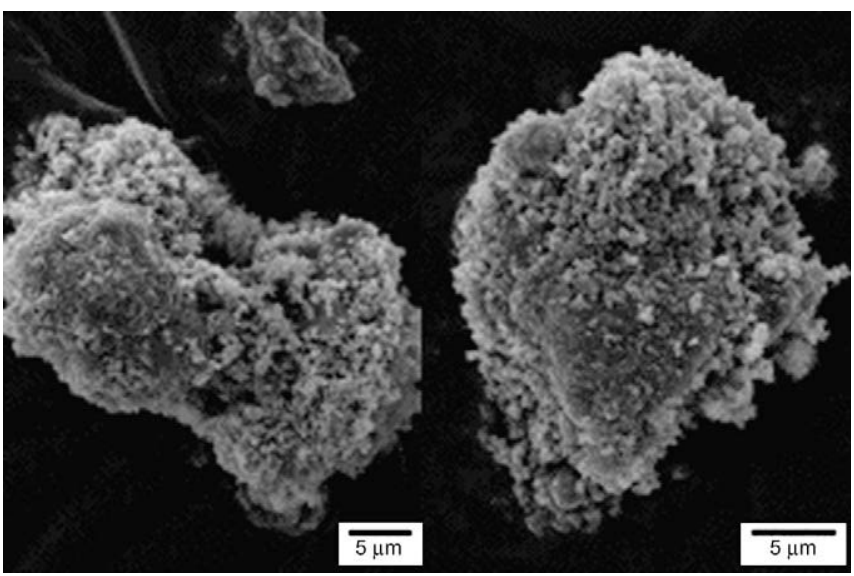

Fig. 6. MEB images of the CsTeV/LM (70/30) phase mixture before (left) and after (right) catalytic test in standard conditions at $350{ }^{\circ} \mathrm{C}$. to the LM phase and the second to the CsTeV phase. No modification of the morphology was observed after catalytic testing, which tends to confirm the hypothesis.

This support effect explains the catalytic results obtained. The decrease in active phase mass in the catalysts is balanced by the absence of sintering of the later phase. The positive effect on the selectivity to MAA and MA is more difficult to explain. it may be hypothesized that the small size of the active CsTeV particles allows better thermal exchanges with the gas phase avoiding hot spot on the catalysts, thus avoiding over-oxidation. The lanthanum molybdate may also be involved. Although it is not very active, it is very selective to isobutene which is an intermediate of the reaction; this may have a direct positive effect on the selectivity since isobutene is very selectively transformed into MAA and MA over the CsTeV catalysts, but also an indirect effect since isobutene oxidation will help to maintain the polyoxometallate phase in a more reduced state, which has been shown to be beneficial to the selectivity in MAA and MA [13]. With such synergetic effect, there

a

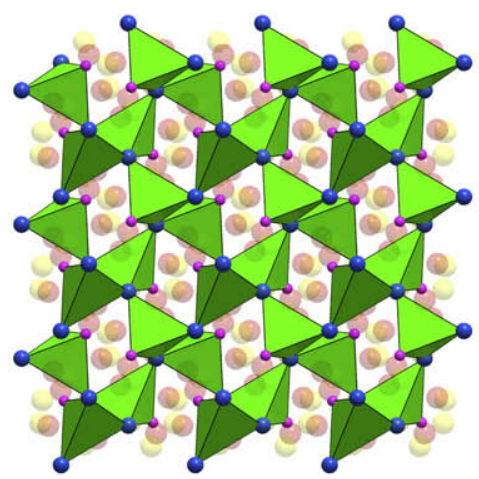

b

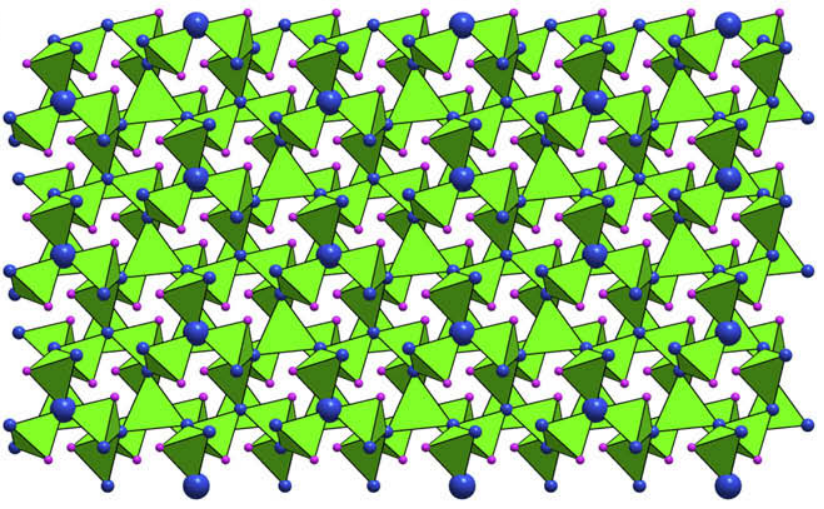

C
C

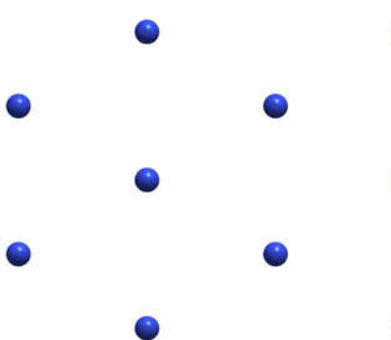

Fig. 7. Crystal structure of $\beta-\mathrm{La}_{2} \mathrm{Mo}_{2} \mathrm{O}_{9}$ (and of $\mathrm{La}_{2} \mathrm{Mo}_{1.9} \mathrm{~V}_{0.1} \mathrm{O}_{8.95}$ ): (a) projection along $(100)$ of the structural framework built up from $\left[\mathrm{O}_{1} \mathrm{La}_{3} \mathrm{Mo}(\mathrm{V})\right.$ in green] antitetrahedra (La corners in blue, $\mathrm{Mo}(\mathrm{V})$ in pink) with partially occupied sites $\mathrm{O}_{2}$ (faded yellow) and $\mathrm{O}_{3}$ (faded red) inserted in the tunnels; (b) projection of the cationic arrangement along (111) threefold symmetry axis, with a highlighted $\mathrm{La}^{3+}$ hexagonal sublattice; (c) isolated La hexagonal array. 
should be an optimal ratio between the LM and CsTeV particle sizes and in the case of the low surface area LMV sample, a lot of CsTeV particles in the 50/50 phase mixture are not mainly stuck to the LMV surface and sintered.

A question that remains is what is specific to the LM phase to allow this support effect, which has never been observed with other phases.

The structure of $\beta$ - $\mathrm{La}_{2} \mathrm{Mo}_{2} \mathrm{O}_{9}$ is rather difficult to describe as usual in terms of cationic coordination polyhedra. This is due to the fact that two out of three oxide sites are only partially occupied (O2 et O3). The structure can better be described in terms of anionic coordination anti-polyhedra [14] (Fig. 7a). The site 01 fully occupied is surrounded by four cations, $3 \mathrm{La}^{3+}+1 \mathrm{Mo}^{6+}$. These
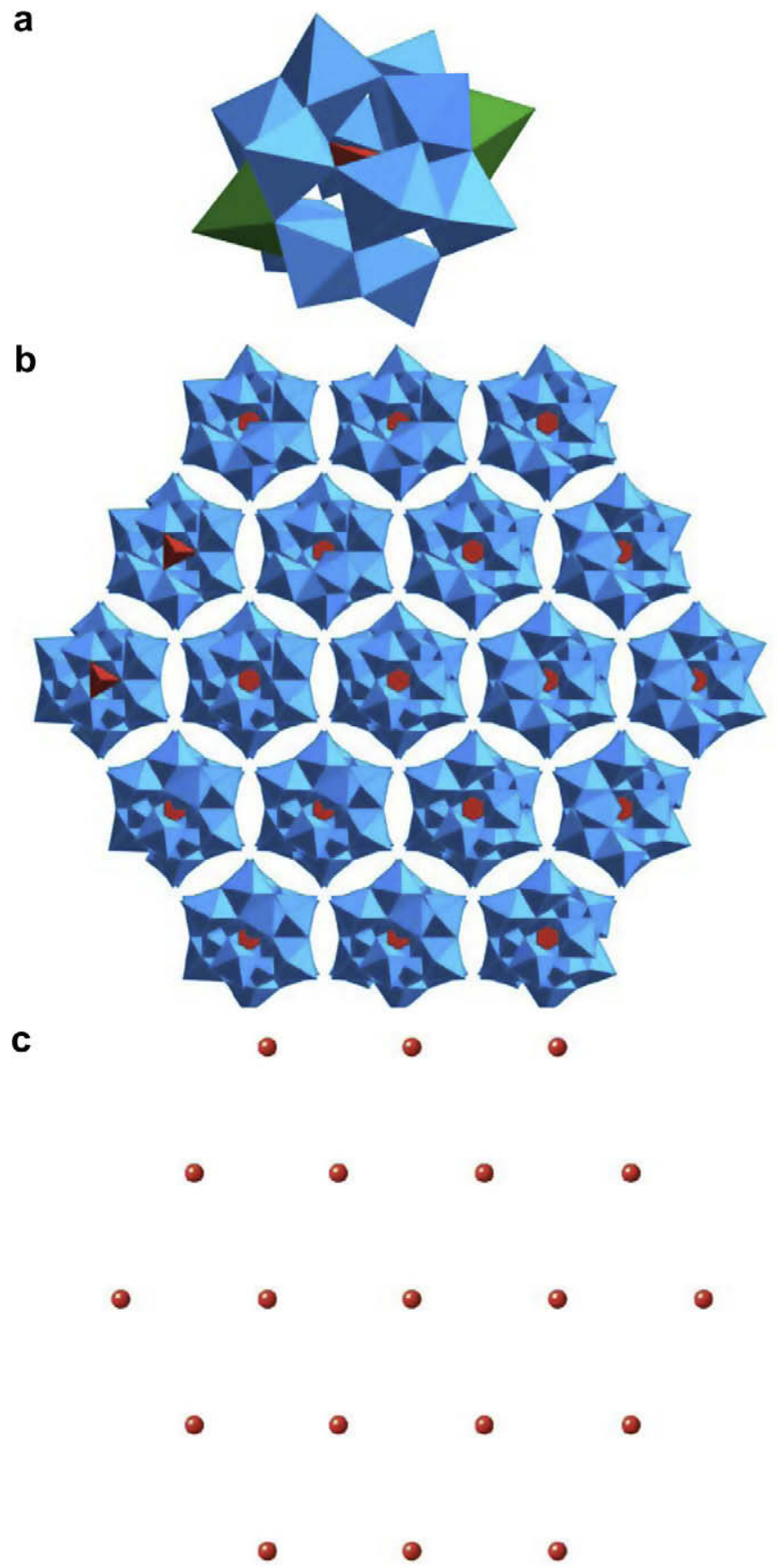

Fig. 8. (a) Structure of the $\mathrm{CsTeV}$ compound, (a) $\left(\mathrm{PMo}_{12} \mathrm{O}_{40}\right)$ Keggin-type heteropolyanions capped by vanadyl cations (green), (b) anionic arrangement in the (111) plane of the cubic cesium salt. The capping cations have been omitted for the clarity of the figure; (c) Isolated P hexagonal array.
[01 $\mathrm{La}_{3} \mathrm{Mo}$ ] anti-tetrahedra are connected to each other by La corners forming a 3D network in green in Fig. 7a. Atoms in 02 and $\mathrm{O} 3$ are located in the channels formed by this network. As it can be seen, Mo and its substituent (V) point out toward inside the channels. When the structure is observed along the (111) direction (see Fig. 7b and c), the complex arrangement of $\mathrm{La}^{3+}$ cations is built up from the interweaving of hexagonal sublattices, one of which is highlighted as larger blue spheres in Fig. 7b. The LMV phase crystallizes in this $\beta$ structural type with room temperature cubic parameter $0.71458 \mathrm{~nm}$ [15].

The structure of he CsTeV compound can be described as an arrangement of $\left(\mathrm{PMo}_{12} \mathrm{O}_{40}\right)$ anions capped with Te and VO cations with $\mathrm{Cs}$ and protons as counter-cations. The $\left(\mathrm{PMo}_{12} \mathrm{O}_{40}\right)$ anions have the well-known $\alpha$-Keggin structure composed of a central tetrahedral $\mathrm{PO}_{4}$ surrounded by 12 edge-sharing metal-oxygen $\mathrm{MoO}_{6}$. The surface of the $\alpha$-Keggin assembly exhibits four cavities defined by eight-membered $\left(\mathrm{Mo}_{4} \mathrm{O}_{4}\right)$ rings where the $(\mathrm{VO})^{2+}$ and $\mathrm{Te}^{4+}$ cations are located. One of these cavities (or two opposite to produce idealized point symmetry) is occupied. The oxidation state of vanadium and tellurium cations has been demonstrated to be $4+$ and the pyramidal geometries of the sites are likewise consistent with

\section{a}

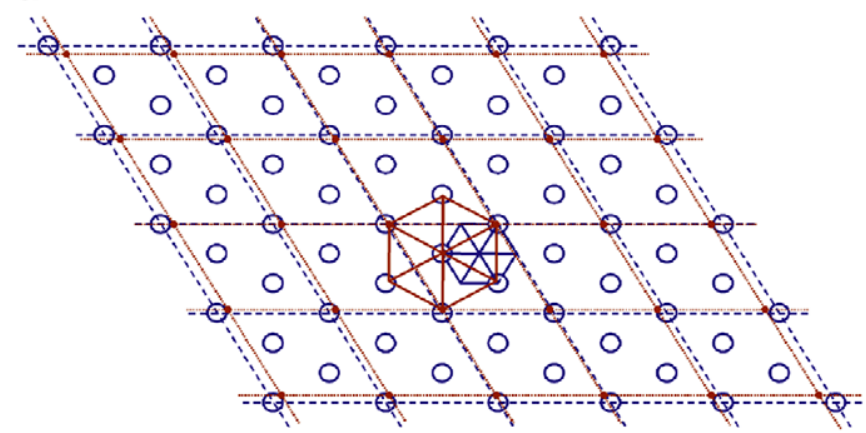

b

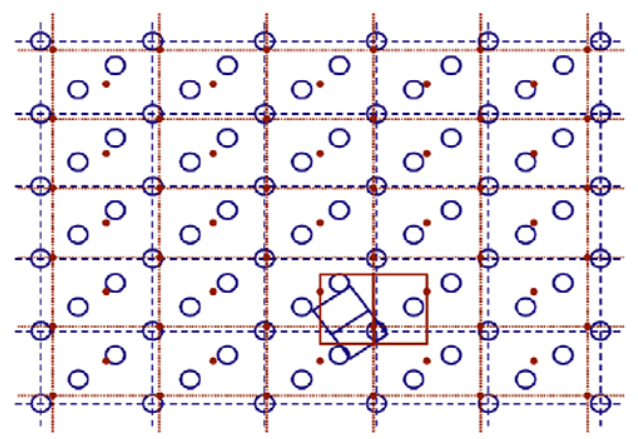

C

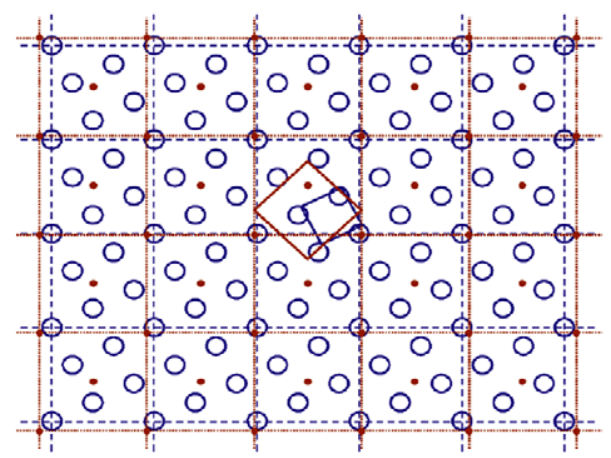

Fig. 9. Fit between the P array in CsTeV (red dots and dotted lines) and the La array in LMV (blue circles and dashed lines) along the 3 main cubic directions of both lattices: (a) along (111) with covering rate 50\% and misfit $8.74 \%$; (b) along (110) with covering rate $40 \%$ and misfit $8.74 \%$; (c) along (100) with covering rate $28.6 \%$ and misfit $8.70 \%$. Note that the P lattice is either slightly expanded ( $\mathrm{a}$ and $\mathrm{b}$ ) or slightly contracted (c) relative to the La lattice. 
$\mathrm{Te}^{4+}$ and $(\mathrm{VO})^{2+}$ centers with the stereochemically active lone pair and the vanadyl oxygen, respectively, occupying the vacant apical site (in green in Fig. 8a) [5]. To balance charges in the capped anions, molybdenum cations are reduced. But it has not been possible to determine the extent of reduction of Mo in the capped anions neither whether the anions are single or bi-capped or both.

The mixed proton and cesium salt crystallized with a cubic cell with cell parameter equal to $1.1824 \mathrm{~nm}$ [5]. The structure of the cubic cesium salt in the (111) plane is presented in Fig. 8b with the $\mathrm{P}$ arrays in this plane. $\mathrm{P}$ atoms being in central position in the Keggin anions, this array can be considered that of the Keggin anions.

Interestingly, when La arrays in the LMV phase and the P (Keggin-type anions) arrays in the cesium phosphomolybdic salt structures are superimposed, a good fit was obtained (Fig. 9). Presumably $\mathrm{OH}$ surface basic sites bound to the La cations are substituted by phosphomolybdic anions leading to strong and coherent boundaries between lattices of the two phases and to the stabilization of the salt particles at the surface of the lanthanum molybdate. The "covering rate", defined as the total number of matching atoms over the total number of atoms in the $\mathrm{P}$ and La arrays, is larger in the (111) plane (50\%) than in the (110) and in the (100) planes (40\% and $28.6 \%$, respectively). The misfits between the arrays have been calculated in terms of difference of unit cell surface determined by the La and P arrays. These misfits were of about $8 \%$, which is not small but could still lead to efficient boundary conditions [16]. The phosphomolybdic particles are much smaller than the lanthanum molybdate particles and the surface contact is limited which should allow relaxing the misfit accumulated. Furthermore, the structure of the salt could easily absorb the local lattice strain generated by the misfit.

The lanthanum molybdate would thus play a role of support for the polyoxometallate active-phase particles, avoiding their sintering in the reaction conditions and consequently maintaining their high catalytic activity. Although it is not clear yet if it is because of the intrinsic properties of the lanthanum molybdate or if it is related to the supporting effect, the selectivity of the catalysts appeared improved. It is also the case for the stability of the catalyst, which was already high for the pure active phase [5].

\section{Conclusion}

Several conclusions can be drawn from this study:

1. Very efficient catalysts for the oxidation of isobutane can be prepared by mechanically mixing a phosphomolybdic polyoxometallate with cesium tellurium and vanadyl as counter-cat- ions, and a lanthanum molybdate either pure or with molybdenum partially substituted by vanadium, which is poorly active and mainly selective to isobutene.

2. The synergetic effect observed between the two phases has been explained by a support effect. The heteropolycompound particles, which are much smaller than the lanthanum molybdate ones, are evenly adsorbed on the laters avoiding their sintering, which occurs during the first hours under stream. With up to $50 \%$ of lanthanum molybdate in the phase mixtures, the activity of the catalyst remained almost the same as that of the pure phosphomolybdic polyoxometallate whereas the selectivity to MAA and MA slightly increased. The observed catalytic properties also appeared very stable with time.

3. The support effect avoiding the sintering of the active phase particles can tentatively be explained by the existence of coherent phase boundaries between the two phases and more specifically the La array in the lanthanum molybdate and the Keggin unit array in the polyoxometallate salt. These fits should help for the development of a stronger bonding between the particles enhancing the anchorage of the polyoxometallate particles at the surface of the lanthanum molybdate. This type of synergetic effect had never been reported in catalytic oxidation reaction for which most of the time it is the spreading of one phase on the other which is at the origin of a synergetic effect.

\section{References}

[1] S. Yamamatsu, European Patent 425 666, Asahi Kasei Kogyo Kabushiki Kaisha, 1989.

[2] K. Nagai, Y. Nagaoka, H. Sato, M. Ohsu, European Patent 418,657, Sumitomo Chem. Co., 1990.

[3] T. Kuroda, Japanese Patent 4059738, Mitsubishi Rayon Co., 1992.

[4] Q. Deng, S. Jiang, T. Cai, Z. Peng, Z. Fang, J. Mol. Catal. A 229 (2005) 165.

[5] Q. Huynh, Y. Shuurmann, P. Delichere, S. Loridant, J.M.M. Millet, J. Catal. 261 (2009) 166.

[6] P. Lacorre, F. Goutenoire, O. Bohnke, R. Retoux, Y. Laligant, Nature 404 (2000) 856.

[7] Q. Huynh, P. Lacorre, J.M.M. Millet, WO Patent 2007/0937, CNRS, 2008.

[8] G.-Y. Adachi, N. Imanaka, Chem. Rev. 98 (1998) 1479.

[9] H. Imai, M. Nakatsuka, A. Aoshima, Japanese Patent 62132832, Asahi Chem. Ind. Co., 1987.

[10] W. Li, W. Ueda, Catal. Lett. 46 (1997) 261.

[11] B. Ernst, T. Haeberle, H.J. Siegert, W. Gruber, US Patent 5380932, Sumitomo Chem. Co., 1995.

[12] M. Baca, M. Aouine, J.L. Dubois, J.M.M. Millet, J. Catal. 233 (1) (2005) 234

[13] W. Li, W. Ueda, Stud. Surf. Sci. Catal. 110 (1997) 433 (3rd World Congress on Oxidation Catalysis, 1997).

[14] G. Corbel, Y. Laligant, F. Goutenoire, E. Suard, P. Lacorre, Chem. Mater. 17 (2005) 4678.

[15] A. Selmi, Ph.D. thesis, Université du Maine, 2007.

[16] J.G. Eon, P. Courtine, J. Solid State Chem. 32 (1980) 67. 